\title{
artículos
}

\section{Arte y peste: Desde el medievo al ochocientos, de la mitología a la realidad local}

\author{
Milagros León Vegas \\ Universidad de Málaga
}

\section{RESUMEN}

El impacto de las epidemias en la historia es constatable desde todos los ámbitos de producción intelectual y artística del hombre. La pintura, además de hacerse eco de estos desastres, constituye una de las fuentes más interesantes para aproximarse a la interpretación dada a los mismos por las distintas sociedades, dejando entrever datos de rigor histórico, así como elementos englobados dentro del complejo mundo de las mentalidades. La peste negra sufrida por Europa, en la segunda mitad del siglo XIV, supone un punto de inflexión en la representación de la muerte, quien en forma de esqueleto o ser fantasmagórico triunfa sobre la vida, perpetuándose esta visión hasta la centuria del Ochocientos. Algunas de las obras más destacadas y conocidas, centradas en este capitulo infeccioso, nos servirán para entender su significado en el devenir de los tiempos, con especial detenimiento en el siglo XVII y zonas geográficas concretas, donde la enfermedad dejó, además de un reguero de muertos, un lienzo como documento gráfico de lo ocurrido.

PALABRAS CLAVE: Arte/ peste/ Medievo/ siglo XVIII/ Mitología.

The Art and the Pestilence. Since Middle Ages to XIX th, since Mythology from Local Reality

ABSTRACT

The impact of the epidemics in history is verifiable from all the scopes of intellectual and man's artistic production. The painting, besides to become echo of these disasters, constitutes one of the most interesting sources to come near to the interpretation given to such by the different societies, leaving glimpsing data of historical rigor as well as elements included within the complex world of the mentalities. The black plague undergone by Europe in second half of century XIV, supposes a point of flexion in the representation of the death, that in form of skeleton or phantasmagoric being prevails on the life, being perpetuated this vision until the century of the Eight hundred. Some of the most outstanding and known works, centered in this infectious chapter, will serve to understand us their meaning in happening of the times, with special thoroughness in the century XVII and concrete geographic zones where the disease left in addition to a drip of died a linen cloth like schematic of the happened thing. KEY WORDS: Art/ Plague/ Middle Ages/ XVIIIth/ Mithology.

MANifEstaciones aRTÍsticas de los gRANDES CONTAgIOS SUFRIDOS POR LA HUMANIDAD.

La pintura ha sido siempre, desde época ancestral, una forma de expresión del hombre para volcar sus pensamientos, miedos, la percepción de la realidad inmediata, de lo comprensible a su entendimiento y lo desconocido, del horror, de lo grotesco y lo bello, transformando lo efímero e inmaterial en eternos testimonios de un periodo, bajo

* LEÓN VEGAS, Milagros: "Arte y peste: Desde el medievo al ochocientos, de la mitología a la realidad local", en Boletín de Arte, $\mathrm{n}^{\circ}$ 30-31, Departamento de Historia del Arte, Universidad de Málaga, 2009-2010, págs. 223-238. 

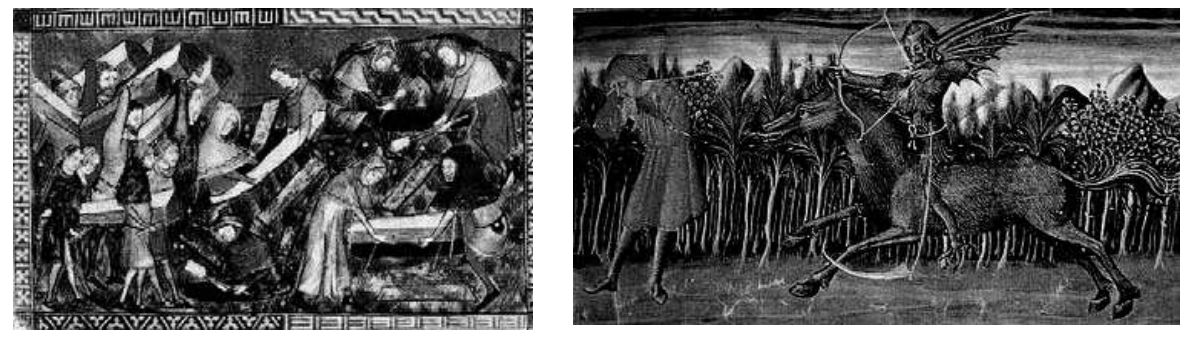

1. "Enterrando a las víctimas de la peste de Tournai", ANÓNIMO, 1349.

2. "Triunfo de la muerte", Miniatura, ANóNIMO, siglo XV.

la mirada siempre personal del artista. Las fuentes de inspiración son muchas, y no siempre se encuentran en elementos sublimes o en hechos extraordinarios y provechosos para el conjunto de la comunidad coetánea. Las guerras, los desastres naturales o las enfermedades repercuten hondamente en las conciencias colectivas, de ahí que copen un amplio porcentaje de la manufactura plástica de las distintas sociedades.

El objetivo de este apartado no es, sin embargo, enumerar las creaciones influidas por el drama de una infección, ni tampoco resultar exhaustivos a través de una completa lista bibliográfica sobre las publicaciones referidas al tema tratado. Nuestro estudio se ciñe en repasar las composiciones más significativas, mientras esbozamos el actual panorama historiográfico, a fin de dimensionar la relevancia de los efectos ocasionados por un contagio en las trazas de algunos maestros del pincel.

En la todavía parca nómina de investigaciones, el principal binomio se establece entre medina y pintura ${ }^{1}$. En nuestro país, durante la década de los sesenta del siglo XX, comienzan a traducirse obras versadas en esta cuestión, aunque la producción científica por parte de profesionales sanitarios e historiadores del arte españoles arranca en los años setenta de la citada centuria. Siguiendo un orden cronológico o por sintomatologías, los distintos autores consideran los cuadros más representativos de la práctica médica a lo largo del tiempo, en extensas monografías convenientemente ilustradas. Dentro de la mayoría de trabajos, las infecciones tienen un capítulo propio por la dureza de sus secuelas. No obstante, también encontramos estudios centrados en contagios, con especial atención hacia la peste, los cuales

Fecha de entrega: Mayo de 2009.

${ }^{1}$ HOLLÄNDER, E.: La medicina a través de la pintura, Barcelona, Ariel, 1962 (traducción de la cuarta edición alemana); ROUSSELOT, J.: La medicina en el arte, Argos, Barcelona, 1971; GRANJEL, L.: La medicina en la pintura: Colección de los museos de Europa, Madrid, Antiobióticos, 1972; GÓMEZ-SANTOS, M.: La medicina en la pintura, Madrid, Ministerio de Educación y Ciencia, 1978; ARíS FERNÁNDEZ, A., Medicina en la pintura, Madrid-Barcelona, Lunwerg, 2002; PORTUGAL ÁLVAREZ, J. de (et alii): El arte y la práctica de la medicina, Barcelona, Grupo Ars XXI de Comunicación, 2006; TOPOLANSKI, R.: El arte y la medicina, Montevideo, 2008 [e-book, recurso electrónico disponible en: http://dcmedicina.edu.uy]; y VIGUÉ, J. y RIC- 

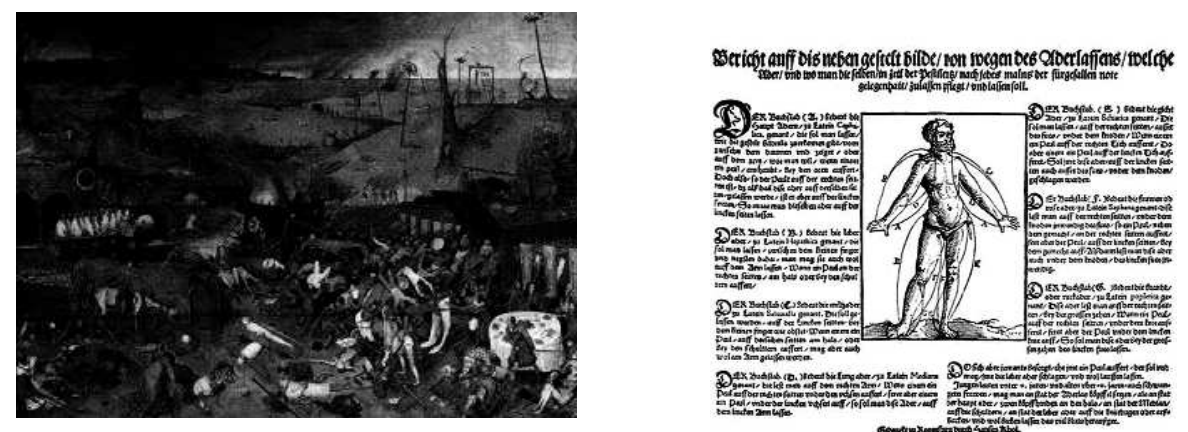

3. "El triunfo de la muerte", PEATER BRUHEGEL, 1560.

4. "El sangrador", MICHAEL OSTENDORFER, 1555.

delimitan y completan la imagen de la letal enfermedad, a través de determinadas composiciones pictóricas ${ }^{2}$.

En todos los escritos señalados, el punto de partida o de conjunción entre arte y práctica médica se sitúa en la Prehistoria. Precisamente, la autoría de gran parte de los primeros pictogramas descubiertos en cuevas se adjudica a chamanes o magos consagrados a proveer, entre otras cosas, la salud. La interpretación dada a este tipo de símbolos responde a la necesidad de expresar, de forma efectiva, un fenómeno desconocido en su origen y propagación. Un documento convertido en importante crónica de los hechos más relevantes vividos por una comunidad, reproducido en múltiples versiones a lo largo de los distintos periodos históricos. En consecuencia, desvincular lo "clínico" del pensamiento mágico y supersticioso, de indudables tintes dramáticos, es tarea imposible a la hora de abordar un análisis de las obras propuestas a continuación.

Pese a lo apuntado, nuestra pincelada histórico-artística se centra en la Edad Media, Moderna e inicios de la Contemporánea, al localizar en dichos periodos los testimonios más interesantes sobre peste bubónica. En líneas generales, podemos distinguir tres grandes temáticas, a veces independientes, otras entrelazadas: pesi-

KETTS, M.: La medicina en la pintura. El arte médico, Barcelona, Ars Médica, 2008.

2 Destaca por su extensión y profundidad, a la hora de abordar el tema, la monografía de PRIETO, J.G.F.: Las enfermedades infecciosas en el arte, Barcelona, Ars Médica, 2004; De menores pretensiones, en cuanto a contexto histórico, pero de igual interés encontramos los siguientes títulos: MORÁN SUÁREZ, I.: "El fuego de San Antonio: Estudio del Ergotismo en la pintura del Bosco", Asclepio: Revista de historia de la medicina y de la ciencia, vol. 48, fasc. 2, 1996, págs. 173-194; GONZÁLEZ LÓPEZ, F., "Patología médica y simbolismo en la obra de Durero", Investigación y educación en enfermería, vol. 21, n 2, Antioquia, 2003, págs. 140-143; ORTIZ GONZÁLEZ, A., "Documentos para la historia: las infecciones en el arte a lo largo de tiempo", Cuadernos de Investigación Histórica. Seminario “Cisneros”, n. ${ }^{2} 22,2005$, págs. 401-429; QUILES F., "Resurrección de una escuela. La peste de 1649 y el quiebro en la evolución de la pintura sevillana", Atrio: 

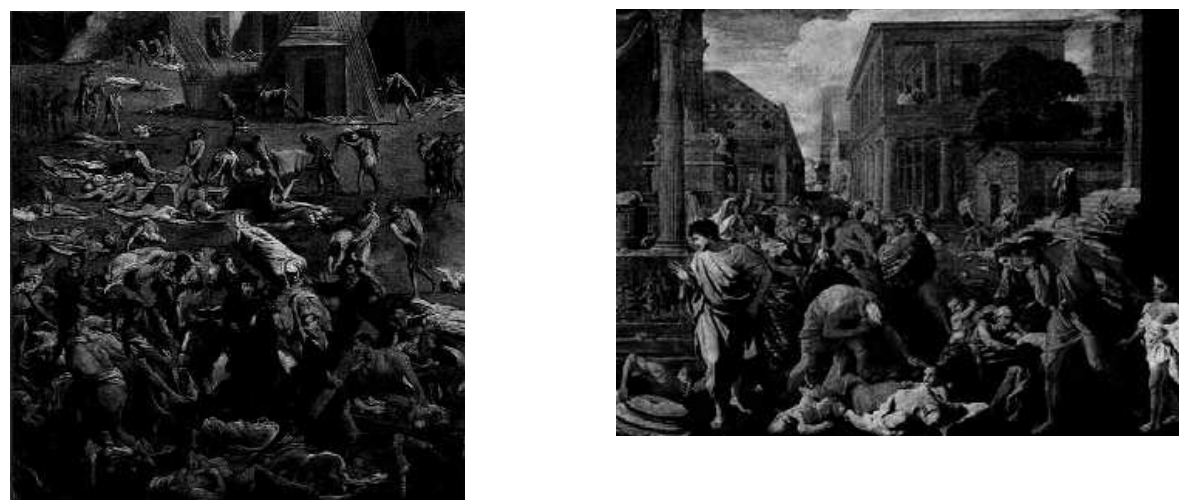

5. "La plaza del mercado de Nápoles durante la peste de 1656" (detalle), DomÉNICo GARGIULO, 1612-1679.

6. "Los filisteos golpeados por la peste o El milagro del Arca", NICOLÁS PoUSSIN, 1630-1631.

mismo ante el mortífero mal, religiosidad supersticiosa y, en una minoría de los casos, ciencia médica.

Ya desde el medievo, los textos incluyen dibujos en los cuales se hace destacable la gran mortalidad aparejada a la plaga y lo inevitable de la misma. Es el caso de una ilustración sobre el enterramiento de las víctimas provocadas por la peste de Tournai en 1349, perteneciente a un manuscrito titulado: Anales de Gilles de Muisit (1272-1353) de Abbot de Saint-Martin ${ }^{3}$. En ella, observamos a una multitud de personajes transportando ataúdes a unas fosas aún no abiertas.

A raíz de la peste negra que asoló el continente europeo en el siglo XIV, el dramatismo del atropellamiento en sepultar a tantos cadáveres desemboca en la macabra figuración de la enfermedad, y su homónima la muerte, en forma de esqueletos o diablos alados, provistos de guadañas, arcos con flechas, a veces bailando entre personajes de distinto rango social, metáfora del poder mortal e igualador de la catástrofe, con independencia del nivel de riquezas y calidad del ser tocado por el infortunio 4 .

La literatura y otras expresiones estéticas repiten continuamente, en esos años de oscurantismo, el tema de la "danza de la muerte", donde ésta es la gran vencedora, siendo su poder superior a la vida de cualquier hombre y a las vanas imprecaciones a la divinidad piadosa y redentora. Una visión fatalista, captada a la perfección por el pintor flamenco Pieter Brueghel "el Viejo", en su abigarrada e impresionante pintura El Triunfo de la muerte $(1560)^{5}$, en la cual detectamos la influencia

revista de historia del arte, $\mathrm{n}^{\circ}$ 12, Sevilla, 2006, págs. 57-70.

3 El manuscrito se encuentra en la Biblioteca Real Alberto I, Bruselas (Bélgica). Véase figura 1 del apéndice.

4 Vid. figura 2: Triunfo de la muerte, detalle de una miniatura de mediados del siglo XV, Siena (Italia). 


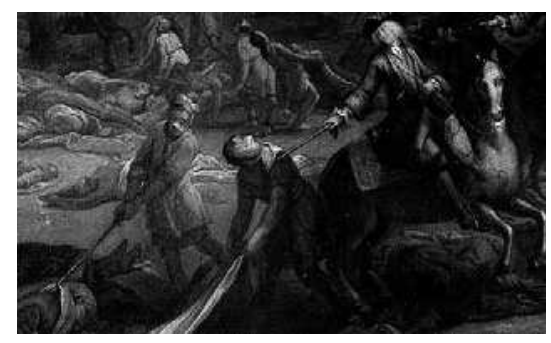

7. "La peste de Marsella en 1720", MICHEL SERRE, 1720-1730.

8. "San Roque como patrón de la peste", PATER PAUL RUBENS, 1623.

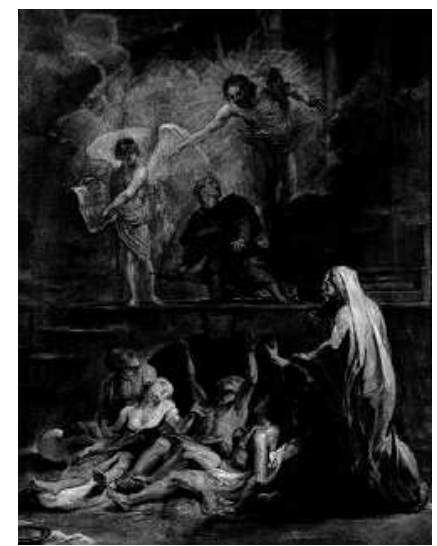

surrealista de El Bosco, extensible al gran formato y la minuciosidad del detalle. Los ecos sombríos y lúgubres de la Edad Media persisten así en el Gótico tardío o albores del Renacimiento, no sólo manteniendo el simbolismo de lo representado sino aumentándolo, en consonancia con la dureza de la peste del siglo XIV. Las incontables figuras y elementos aciagos inundan todo el panel, sin dejar lugar al vacío espacial ni a la lectura esperanzadora de lo plasmado. La sobrecogedora masacre y el dinamismo de la escena, dificultan al espectador captar, con solo una simple aproximación visual, cada una de las imágenes. Las hordas de esqueletos protagonizan la acción al replegar a una multitud de personas hacia un gran féretro, cargar contra reyes, obispos y nobles, incitar al suicidio, realizar ejecuciones y destrucciones de campos cultivados o trasportar cadáveres en el recurrente carro fúnebre, evocador del usado en el carnaval de Florencia.

Los mecenas del arte de esta época, y durante todo el Antiguo Régimen, se suman al sentimiento de culpa por los pecados cometidos, siendo la exacerbación de la fe una de las penitencias más secundadas, sobre todo por la pintura, de ahí la proliferación de la temática religiosa en todo el ámbito cultural europeo6.

Sin embargo, no todo es siniestro y moralizador en el Quinientos pues también vamos a hallar grabados médicos sobre las curas aplicadas a los apestados, fundamentalmente, a fin de ilustrar el método de las sangrías, una de las pocas prácticas sanitarias empleadas contra la mortífera dolencia. Sirva de ejemplo el grabado en madera titulado El sangrador, realizado por Michael Ostendorfer, en Ratisbona (1555) 7 .

En cualquier caso, será en el Barroco donde podemos contemplar grandes obras dedicadas a la epidemia. La pandemia sufrida en Europa, a lo largo del siglo

\footnotetext{
5 Vid. figura 3. La obra se conserva en el Museo del Prado de Madrid. Para más información sobre la misma, consúltese la dirección web: www.museodelprado.es

6 MEISS, M.: Pintura en Florencia y Siena después de la peste negra: Arte, religión y sociedad a mediados del siglo XIV, Alianza Editorial, Madrid, 1988, págs. 91-95.
} 

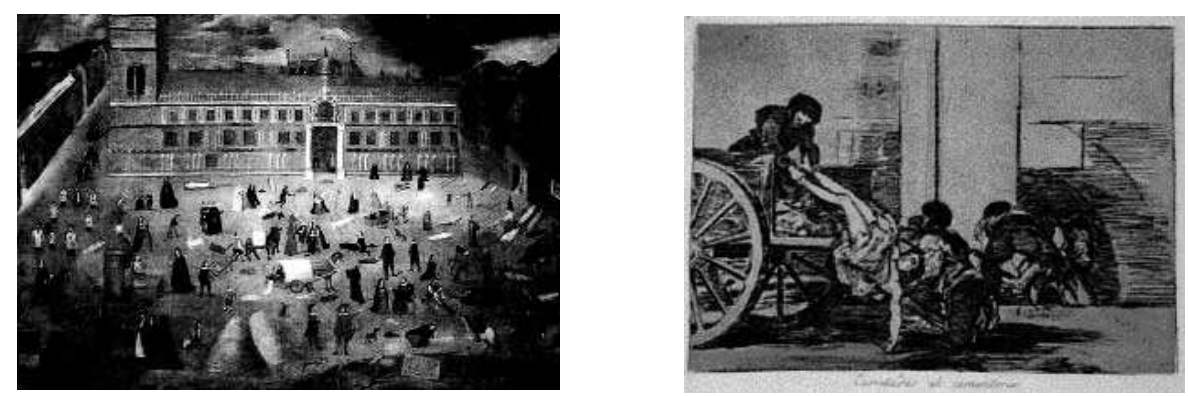

9. "La peste de 1649", ANÓNIMO, siglo XVII.

10. "Desastres de la guerra", FRANCISCO DE GOYA Y LUCIENTES, 1810-1815.

XVII, dejó importantes muestras artísticas, cuya belleza y resonancia en el ámbito cultural son equiparables a la dureza del contagio. En arquitectura, descuella la Iglesia de San Carlos de Viena y las columnas de Milán y Viena. Por su parte, las letras ofrecen novelas tan conocidas como Los Novios, de Manzoni (1842) -ambientada en Lombardía, entre 1628 y 1630-, o Diario del año de la Peste en Londres, de Daniel de Foe (1722) -versada en la plaga de 1665-8.

Geográficamente, la peste del Seiscientos se centra en la zona mediterránea, de ahí que en Italia, Francia y España encontremos las composiciones más representativas de este periodo. La enfermedad sobreviene en dicha centuria a periodos de hambrunas hecho que, junto a la guerra, coloca al hombre de esta época muy próximo a la muerte, alimentando el sentimiento de inestabilidad, pesimismo y desengaño tan definitorio de la mentalidad barroca ${ }^{9}$.

De la producción italiana podemos destacar La plaza del mercado de Nápoles durante la peste de 1656, obra de Doménico Gargiulo (1612-1679) ${ }^{10}$. La mitad de la población napolitana se perdió como consecuencia de esta epidemia, terrible realidad plasmada en la citada hechura, en la cual vemos a una marea humana de vivos

7 Vid. figura 4. Custodiado en el Museo Nacional Germánico, Nuremberg.

8 Las secuelas de la peste no sólo poden rastrearse dentro del género de novela histórica, pues la poesía ofrece también destacados testimonios. Por citar un caso cercano, en la actualidad podemos leer las coplillas y versos que circularon en Cádiz durante la epidemia de 1680-1681, gracias a la recopilación de los mismos por un contemporáneo a los hechos: SAAVEDRA, I. de: Glorisos, sabrados y graves cultos..., Cádiz, 1681, publicación analizada en el trabajo de: CARRASCAL MUÑOZ, J. M. ${ }^{\text {: }: ~ L a ~ g u e r r a ~ d e ~ d i o s . ~ P e s t e ~ y ~ m i l a-~}$ gro en la Bahía de Cádiz (1680-1681), Universidad, Sevilla, 2006, págs. 79-129.

9 Sobre los temas de inspiración barroca y significado de este capital movimiento artístico y cultural, pueden examinarse, entre otros muchos, los siguientes títulos: MARAVALL, J.A.: "La cultura del Barroco: una estructura histórica", en RICO MANRIQUE (coord.): Historia y crítica de la literatura española, vol. 3, tomo 2, 1992 , págs. 364-370, DE LA FLOR, F.R.: Barroco: representación e ideología en el mundo hispánico, (1580-1680), Madrid, Cátedra, 2002 y MÉNDEZ, S.: "Del Barroco como el ocaso de la concepción alegórica del mundo", Andamios: revista de investigación social, n. ${ }^{\circ} 4$, Méjico, 2006, págs. 147-180. 
11. "Napoleón visitando a los apestados de Jaffa el 11 de marzo de 1799", BARÓN GROS, 1804.

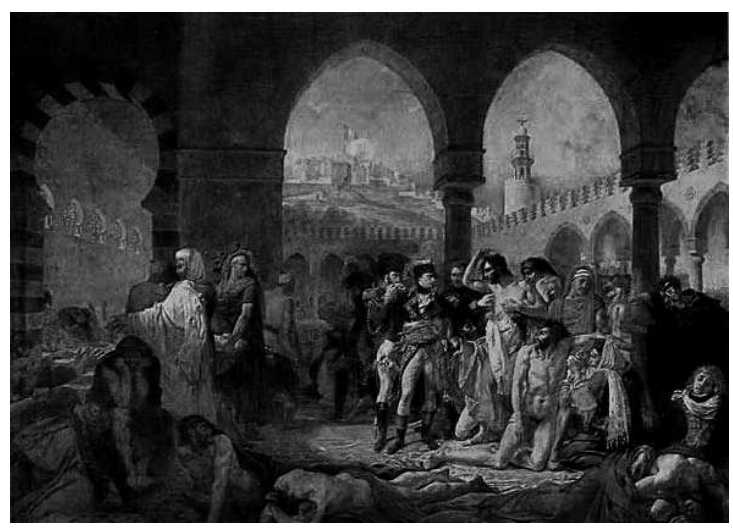

y muertos, donde los primeros a penas dan abasto para recoger a los difuntos y socorrer a los achacosos con algo de agua. Distinguimos a negros portando cadáveres, a las autoridades a caballo intentando dirigir las imposibles tareas de socorro o la estremecedora imagen de una mujer fallecida con su pequeño hijo buscando, inútilmente, algún alimento en su pecho. Este conmovedor recurso iconográfico es usado en otras creaciones hasta bien entrado el siglo XIX, como demuestra La fiebre amarilla, de Juan Manuel Blanes (1871). El impacto emocional de la escena está cargado de simbolismo: la madre muerta representa la tragedia de la humanidad, mientras el niño la eterna esperanza en que la vida logra hacerse paso en medio de la adversidad, con independencia de la crueldad de la misma11.

El italiano Antonio Zanchi nos ofrece otra sugestiva aportación: La peste en Venecia $(1666)^{12}$. De nuevo, se presenta ante nosotros un ambiente sobrecargado de personajes, aunque esta vez ambientado en los canales venecianos, donde la belleza y simetría arquitectónica de los edificios y puentes, junto a la sempiterna presencia de góndolas, contrasta con el desordenado montón de cadáveres apilados en cada uno de estos espacios. Curiosamente, las embarcaciones cargadas de difuntos y guiadas por un gondolero recuerdan a Caronte trasladando almas al infierno. En la parte superior del lienzo, aparece el santo protector de la peste, acompañado de una corte de ángeles, en actitud de anunciar el final del azote. La ciudad flotante es también testigo de la intercesión de protectores como San Nicolás, quien protagoniza el óleo sobre tela Peste de Venecia (1677), realizado por Giovanni Carboncillo.

Por su parte, Nicolás Poussin brinda al Barroco francés el cuadro de: Los filisteos golpeados por la peste o El milagro del Arca, reproduciendo un episodio del Antiguo Testamento, aquel donde Dios castiga a los filisteos con una oleada

10 Vid. figura 5. Museo di San Martino, Nápoles.

11 CHIANCONE, P.: "La peste y la pintura", [recurso electrónico disponible en: http://www.smu.org.uy/historia/pintura.pdf] 


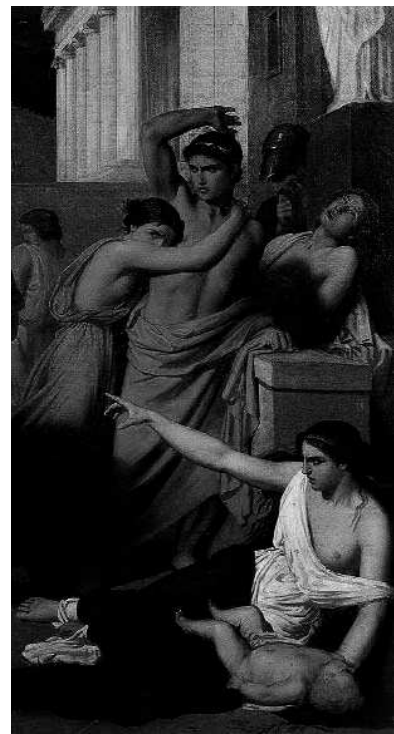

12. "La Peste de Tebas", CHARLES FRANÇOIS JALABEAT, 1819-1901.

de peste por sustraer el Arca de la Alianza a los israelitas ${ }^{13}$. La inspiración la encuentra el autor en la descripción de la epidemia milanesa de 1630 descrita por Manzoni. En un marco de edificios clásicos, podemos identificar el templo de Dagón a la izquierda de una larga calle central —utilizada como punto de fuga visual para dar profundidad a lo representado-, y a varios grupos de personajes en posiciones algo forzadas con el fin de apreciar el semblante de cada uno de ellos, el "affetti" buscado por el artista, donde el gesto se corresponde con una actitud mental, para imprimir la carga dramática adecuada a los hechos inmortalizados, en sintonía con la teatralidad de la estética barroca. Asimismo, los individuos del primer plano se articulan a igual altura y en horizontal, al estilo de los frisos romanos, entre quienes reconocemos, de nuevo, a la madre moribunda con su hijo en el centro de la composición. Poussin propone así, reflexionar sobre el sombrío y desdichado destino de los osados que deciden enfrentarse a Dios.

Aunque adscritas a un Barroco tardío y referidas a una pandemia del siglo XVIII, las tres pinturas dedicadas por Michel Serre a La peste de Marsella en 1720, describen el caos acontecido en la urbe portuaria a consecuencia del contagio, donde resulta casi imposible distinguir los cadáveres de los pocos hombres vivos afanados en apilar a los fallecidos para su posterior enterramiento ${ }^{14}$. Entre la maraña de cuerpos, resaltan las autoridades a caballo bien ataviadas de indumentaria e incluso con peluquín, indicando con varas las tareas a realizar para limpiar el puerto. Sin embargo, lo más destacable es el trasfondo de lo visual, la lectura de la vivencias directas del artista catalán, cuya participación activa, ese preciso año en la ciudad francesa ayudando a sepultar cadáveres e invirtiendo el capital acumulado por su producción pictórica en auxiliar enfermos, mientras muchos personajes ilustres y autóctonos de la zona huían del contagio-, impregna toda la obra ${ }^{15}$. Sus creaciones sobre la infección

\footnotetext{
12 Museo de Bellas Artes de Viena.

13 Vid. figura 6. Museo Nacional del Louvre.

14 Vid. figura 7. Museo de Bellas Artes de Marsella. Sobre esta obra, mírese el siguiente enlace: REGíS, B.: "La iconographie de la peste de Marseille", [recurso electrónico disponible en: www.msh.univaix.fr/recueil/htmlbertrand/winbertrand.html-134k-].
}

15 VILLALVA y GUITARTE, J.: Epidemiología española o historia cronológica de las pestes, contagios, epi- 


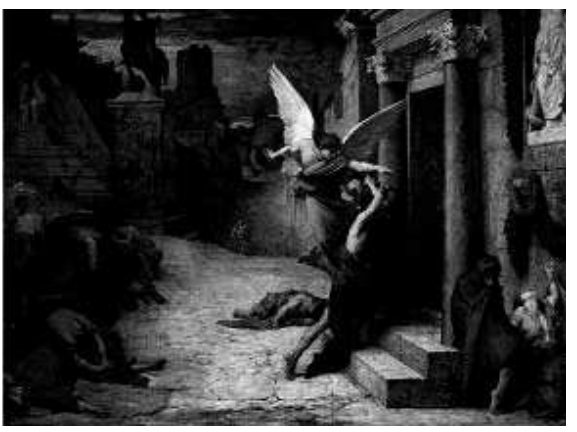

13. "Peste en Roma", JULES ELIE DALAUNAY, 1869 .

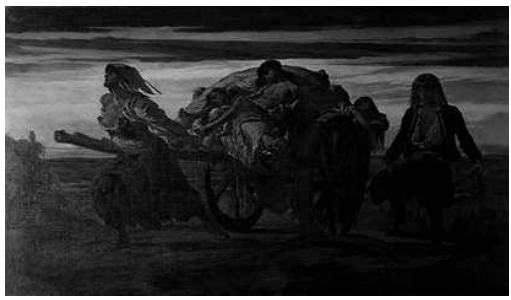

14. "La Plaga de Elliant", LOUS-JEANNOËL DUVEAU, 1849.

de Marsella deben tomarse como un testimonio directo del desastre.

El Barroco español atesora también numerosos lienzos versados en el tema de los contagios. En primer lugar, reseñamos La muerte, de Antonio Arias Fernández ${ }^{16}$. En este óleo tenebrista identificamos el mal con un esqueleto provisto de arco y flechas, con las cuales hiere a niños, mujeres, hombres y entre éstos a soldados, reyes e incluso dignatarios de la Iglesia. Mucho recuerda a las dos tablas de jeroglífico sobre las postrimerías humanas, realizadas por Valdés Leal para la iglesia del Hospital de la Caridad de Sevilla, en 1672, aunque en este último caso no se trate de una referencia a la muerte repentina y cruel ocasionada por la peste, sino a aquella irremediable y encontradiza con todos los seres humanos en un momento de la vida ${ }^{17}$.

Las representaciones de santos se multiplican en el siglo XVII, fieles a las directrices del Concilio de Trento —no sólo en España, sino en todos los países católicos-; entre ellas, las dedicadas a patronos de la peste como San Sebastián, San Roque o San Carlos Borromeo. El primero de los mencionados está relacionado con la calamidad por el símil de la misma con las flechas de su martirio, aunque su fama redentora no se difundió hasta el siglo XVI. El dramatismo del San Sebastián de Ribera es buena muestra de la mentalidad barroca que inspira dichas pinturas. Por el contrario, los otros dos santos sí asistieron personalmente a los contagiados, de ahí que aparezcan en actitud de socorro y caridad hacia ellos, como demuestra el lienzo ejecutado por Francisco Camilo para la Catedral de Salamanca, donde se muestra a San Carlos Borromeo intercediendo ante Jesús y la Virgen por la salud de los mila-

demias y Epizootias que han acaecido en España desde la venida de los cartagineses hasta el año 1801..., Imprenta de Fermín Villalpando, 1803, págs. 104-105.

16 Colegio del Cardenal de Lugo de Monforte de Lemos.

17 El pintor sevillano en sus alegorías Finis gloriae mundi y In ictu oculi, trata sobre la vanidad humana, lo efímero de los bienes terrenales y la brevedad de la vida terrena, utilizando los mismos elementos que en siglos anteriores, es decir, esqueletos, guadañas, cadáveres de representantes de las distintas esferas 


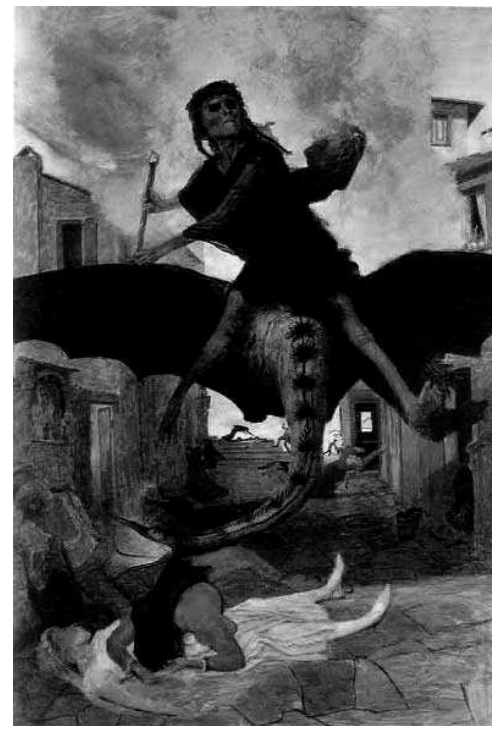

15. "La peste", ARNOLD BÖCKLIN, 1898. neses, o la tabla brindada por Pater Paul Rubens a San Roque como patrón de la peste $(1623)^{18}$. En esta última obra contemplamos el episodio en el que el santo, acompañado de su inseparable perro, es nombrado por Cristo protector ante la tragedia de la peste, según se recoge en la tablilla sostenida por un ángel, mientras, en el plano inferior, seis figuras solicitan auxilio para recuperar la salud perdida.

Pero sin duda, la pintura barroca en guardar mayor relación con la que es objeto principal de nuestra atención -y al mismo tiempo, de las pocas cercanas a la realidad vivida en una localidad española concreta-, es la conservada en el Hospital del Pozo Santo de Sevilla. De autor desconocido, está consagrada a $\mathrm{La}$ peste de $1649^{19}$. El marco elegido para desarrollar la acción es la plaza inmediata al antiguo Hospital de las Cinco Llagas (hoy Parlamento de Andalucía), el cual ocupa el plano superior de la tela, junto a restos de montes situados en las afueras

de la ciudad hispalense, donde se pueden ver las llamas humeantes de las hogueras prendidas para destruir ropas y utensilios contaminados por el mal. En la explanada entre el centro benéfico y la muralla (perceptible en el margen inferior) emerge gran cantidad de gente, congregada en su mayoría para poder ser asistida en las dependencias "sanitarias". Vemos también a autoridades a caballo, cadáveres esparcidos sin ningún decoro, gentes arrodilladas rezando, apestados trasladados en sillas de mano y carretas... Pese a la precariedad técnica del autor, el testimonio histórico desprendido de su análisis es una prueba más, junto a la documentación conservada sobre el contagio de mediados de siglo, de las terribles dimensiones alcanzadas por la hecatombe vírica.

El siglo XVIII español, y parte del XIX, ofrece también imágenes de la plaga, sobre todo, de manos del ilustre zaragozano Francisco de Goya y Lucientes y sus "pinturas negras". Tal es el caso de uno de los lienzos custodiados en la colección

sociales. Vid. RODRÍGUEZ G. DE CEBALLOS, A.: "El sueño de la vida y el triunfo de la muerte en la iconografía del barroco español", Boletín de Arte, n 13-14, Málaga, 1992-1993, págs. 7-30.

18 Vid. figura 8 del apéndice. Museo Thyssen-Bornemisza, Madrid.

19 Vid. figura 9 del apéndice. Museo del Hospital del Pozo Santo, Sevilla. Sobre el cuadro y el contexto his- 


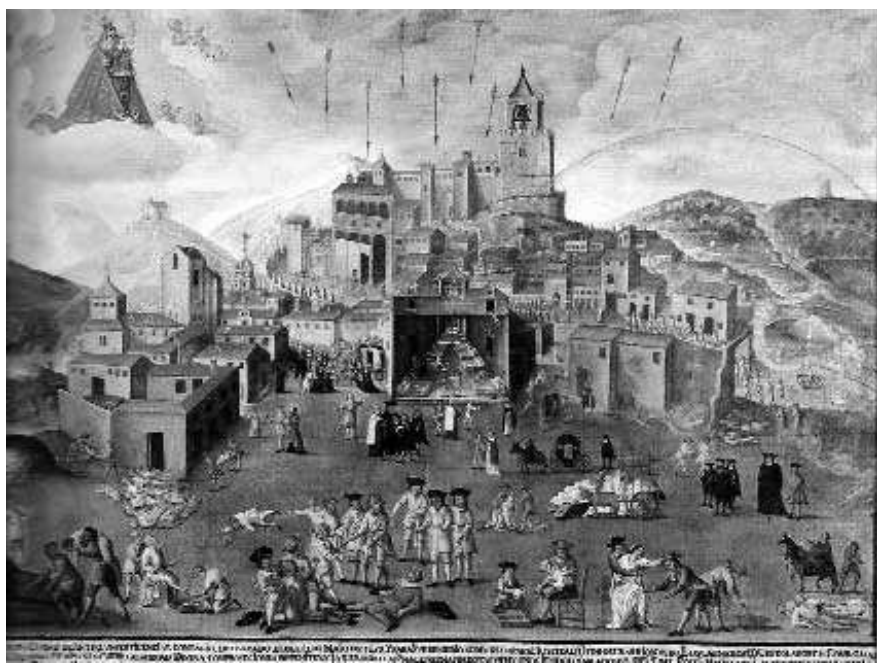

16. "La epidemia de peste", ANÓNIMO, 1732.

particular del Hospital de Pestíferes de Madrid, titulado La Peste (1823). Los enfermos apilados en la esquina de una habitación oscura, presumiblemente un hospital o una casa particular, se consuelan y socorren unos a otros entre abrazos o con algo de agua, mientras protegen sus rostros con telas, para evitar inhalar las exhalaciones pestilentes del familiar asistido. Los grabados de los Desastres de la Guerra también contienen escenas de apestados, en concreto, de carretas repletas de cadáveres. La ocupación francesa de comienzos del Ochocientos, vino acompañada de hambrunas y epidemias, una trilogía mortífera con graves secuelas en la población española del momento20.

EI Neoclasicismo del siglo XIX no excluye la representación de esta calamidad. Es en Francia donde encontramos los mejores ejemplos, en algunos casos a modo de crónica de hechos coetáneos. Tal es la obra del francés Barón Gros titulada: Napoleón visitando a los apestados de Jaffa el 11 de marzo de 1799 (1804), donde vemos a Bonaparte reconociendo a los miembros de su ejército conquistador, tocados por el mal, al final del viaje de regreso a Francia en 179921. Otros siguen apostando por la religiosidad y la esperanza brindada por patrocinadores de la

tórico de la epidemia, contamos con el trabajo de: CARMONA GARCíA, J. I.: La peste en Sevilla, Sevilla, Ayuntamiento, 2004.

20 Vid. figura 10 del apéndice. Museo Nacional de Bellas Artes. Entre los estudios más recientes podemos citar: BALSALOBRE GARCÍA, J. M. a: "Una mirada a Goya: los desastres de la guerra", Espacio, tiempo y forma. Serie V. Historia contemporánea, n 15, Madrid, 2002, págs. 13-24, y PELÁEZ MALAGÓN, J.E.: "La 
Iglesia católica, como Nicolás André Monsiaux, en su obra Abnegación del Monseñor Belzunce, obispo de Marsella, durante la peste que desola esta ciudad en $1720^{22}$.

Simultáneamente, el Ochocientos francés será el momento de inspiración de varios artistas en temas mitológicos centrados en el azote vírico, los cuales rescatan del olvido pasajes y relatos de la antigüedad para protagonizar lienzos como La Peste de Tebas de Charles François Jalabeat (1819-1901)23, donde el autor interpreta lo sucedido en dicha ciudad, desde la serenidad de la distancia en el tiempo y la elegancia del movimiento artístico donde se inserta. En la misma línea, se sitúa la Peste en Roma de Jules Elie Dalaunay (1869) ${ }^{24}$. Esta composición logra un curioso sincretismo entre vida y muerte, paganismo y cristianismo. Así el imperturbable clasicismo de las construcciones —donde podemos reconocer, al fondo, la estatua ecuestre de Marco Aurelio y, en el margen superior derecho, la de Esculapio (dios romano de la medicina) - , se ve salpicado con cuerpos de apestados en los laterales, mientras la escena central la protagonizan dos ángeles, uno alado que indica a otro, de aspecto más tenebroso y provisto de un chuzo, cuántas veces debía golpear las puertas de las casas, traduciéndose en número de muertos por familia u hogar.

De evocación legendaria es La Plaga de Elliant, de Lous-Jean-Noël Duveau $(1849)^{25}$. Esta pequeña población cercana a Cornualles, de donde era natural el antedicho, se vio totalmente devastada por la peste negra del medievo, hasta el punto de quedar, según los relatos de la época, sólo dos supervivientes. La tradición oral rescata este episodio del olvido a través de cantos donde se narra el momento aquí representado: la de una madre arrastrando en dirección al cementerio un carro con los cadáveres de sus nueve hijos, mientras el marido impasible, silbando, encarna la locura consecuente a tanto dolor.

Por último, no podemos dejar pasar la alegoría más famosa y estremecedora de la pandemia, salida de los pinceles del basiliense Arnold Böcklin, quien imbuido en la corriente Simbolista, se hace eco de las primitivas figuraciones del morbo, donde un jinete galopando por el campo y las ciudades solía personificarla, según aparece en su creación al temple, La peste (1898) ${ }^{26}$. En ella la oscura y desfigurada muerte, provista de su terrible guadaña, cabalga sobre los lomos de un dragón mientras va sesgando la vida de quien encuentra a su paso por las calles de una población inventada, en medio de una atmósfera solemne y aterradora a la vez.

Finalizado este breve repaso por la historia de la pintura, con el tema de la peste por argumento, estamos en condiciones de centrarnos en un lienzo singular, donde medicina, religión, urbanismo, leyenda y realidad se dan la mano para configurar una obra de arte, que si bien no destaca por la belleza de su dibujo, constituye el testimonio gráfico más interesante, detallado y fidedigno ofrecido sobre una epidemia.

serie Los desastres de la guerra de Francisco de Goya y Lucientes”, Clío, n³1, 2005.

21 Vid. figura 11. Museo del Louvre, Paris

22 Museo del Louvre, Paris.

23 Vid. figura 12. Museo de Bellas Artes de Marsella.

24 Vid. figura 13. Museo de Orsay, Essonne (Francia). 
Una crónica sobre la peste en Antequera: El cuadro de la EPIDEMIA DE 1679

El caso particular de este estudio es un óleo sobre lienzo fechado en 1732, de autor desconocido, donde se representa el contagio soportado por los antequeranos en los meses de primavera-verano de 1679, bajo el título —no asignado por el artista, pero sí asumido por los trabajos realizados sobre él-, La epidemia de peste $^{27}$. Custodiado por la Pontificia y Real Archicofradía de Nuestra Señora del Rosario, lo podemos contemplar en la nave de la epístola de la Iglesia de Santo Domingo de Antequera, junto al camarín de la Virgen del Rosario, a quien está dedicado como exvoto por su redentora y efectiva intercesión en el recobro de la salud.

A pesar de guardar cierta similitud con el cuadro de la peste de Sevilla de 1649 — por el asunto y, sobre todo, por el esquema compositivo, localizando el hospital al fondo y la explanada inmediata al mismo como principal escenario donde reconocemos la mayor cantidad de personajes-, el que nos ocupa le supera en precisión de pincelada, pero sobre todo, al convertirse en inestimable testimonio de la realidad médica y religiosa de una época dado su cuidado detallismo. En este sentido, son varias las prácticas curativas plasmadas en la franja inferior de la obra. Esta sección se corresponde con unos trazos muy marcados, donde el artista enseña a los personajes como muñecos de expresiones exageradas e indolentes, pero interesantísimos por la información implícita en su figuración. Así, comprobamos como un grupo de cirujanos se emplean en sangrías, cauterización de bubones y aplicación de parches impregnados del aceite de las luminarias de la Virgen del Rosario. Cualquiera de los remedios usados era doloroso, de ahí que encontremos a un mínimo de dos barberos-cirujanos por paciente, pues uno de ellos quedaba responsabilizado de inmovilizar al contagiado. Lógicamente, las inducidas hemorragias buscaban una depuración de la sangre, aunque también pueden tratarse de escisiones sobre el bubón para provocar la supuración rápida del ganglio inflamado evitando, de esta forma, el doloroso estallido natural. Esto último es lo que se practica a un bebé en la ingle con un pequeño bisturí. La maestría del "sanitario" era crucial en esos momentos, pues un corte desafortunado podía afectar un vaso linfático vital y, con ello, provocar unas pérdidas de sangre mortales acelerando, sin duda alguna, el deceso del desdichado. Algo parecido sucedía con la cauterización de los ganglios inflamados pues, se trataba de quemarlos con un hierro candente (normalmente, se utilizaba una especie de braserillo, tal cual se ve en la tela), y generar así una herida y costra, la cual caería con el tiempo. En una de las escenas comprobamos esta actuación sobre una mujer, quien arrebata el sobrero al cirujano, ante la insoporta-

25 Vid. figura 14. Museo de Bellas Artes de Quimper (Francia).

26 Vid. figura 15. Museo Kunstmuseum de Basilea.

27 Vid. figura 16. La ficha técnica de la obra puede consultase en: LEÓN VEGAS, M.: "La epidemia de peste, 1732" en Fiesta y Simulacro, Junta de Andalucía. Consejería de Cultura, Sevilla, 2007, pág. 246-247. Por 
ble sensación de quemazón. Lo lastimoso de estos procedimientos y su dudosa efectividad dan idea de la precariedad médica del siglo XVII. Menos traumáticas eran las aplicaciones de gasas impregnadas del aceite de las lamparillas de la Virgen del Rosario, como especie de ungüento milagroso, capaz de curar por la fe en la sanación por obra mariana. Pese a la sensación inicial, todas las acciones descritas no acontecen en un único tiempo, pues el patrocinador del lienzo, el cirujano Juan Bautista Napolitano, ferviente devoto de la advocación del Rosario, se hace representar como protagonista de cada una de las "instantáneas" de tratamientos medicinales, aunque posiblemente se trate de un anacronismo ya que es incierta su participación en las tareas asistenciales de la peste de 1679.

Justo en la parte central descubrimos el hospital, abierto como si de una casita de muñecas se tratase. En él vemos una gran sala ocupada con numerosas camas y dolientes a quienes se le practican las curas ya relatadas. También aparece un hombre arrojándose por una ventana, fruto de las fiebres delirantes y efectos de la inoculación, suicidio que recuerda a los contenidos en el Triunfo de la muerte de Peater Bruhegel. En cualquier caso, el dato representado es irreal pues, en el siglo $\mathrm{XVII}$, los contagiados eran recluidos en lazaretos emplazados en las afueras de la ciudad para evitar la propagación del virus, a consecuencia de la inhalación de los humos pestilentes. Se reafirma así la ejecución de la obra en el Setecientos, ya que en dicha centuria el Hospital de San Juan de Dios sí atendió todo tipo de padecimientos, al menos hasta la fiebre amarilla de comienzos del XIX, cuando volvieron a habilitarse espacios, más o menos alejados del núcleo poblacional, para aglutinar a los achacosos. En la peste de 1679, estos lugares se concentraron entorno a la calle de Belén y a la Plaza de San Bartolomé, aprovechando las viviendas de particulares, las cuales perdieron algunos de sus muros para formar grandes cuadras donde confinar a los incalculables infectados.

Si bien, no solo aparecen enfermos diseminados por el lienzo, también hay cadáveres como los que asoman en primer plano, en la esquina inferior izquierda, donde distinguimos entre los fallecidos a religiosos capuchinos, hecho nada sorprendente pues eran los primeros en acudir cuando la catástrofe golpeaba a los vecinos de la localidad donde tenían fundado convento, o en otras más o menos próximas, pues interpretaban la tragedia como una llamada divina al servicio del prójimo. En las desembocaduras de las calles y en las afueras de las puertas de acceso a la ciudad, observamos apilados bastantes cuerpos sin vida trasladados hasta esos puntos por los llamados, en las fuentes documentales consultadas, "ganapanes" o "palanquines", es decir personas de baja estimación social, normalmente esclavos, reos o adscritos a minorías étnico-religiosas, quienes buscaban en estas actividades suicidas su libertad, la percepción de cuantiosas remuneraciones e, incluso, el pillaje entre las posesiones personales de los finados, todo lo cual nada valía en caso de perecer ellos mismos, como ocurría en la mayoría de las ocasiones, de ahí la dificultad de encontrar gente dedicada a esta labor, a la que se unían otras con no menos riesgo de contaminación. Nos referimos a la recogida de objetos presuntamente "manchados" por el 
mal, sobre todo textiles, aunque no faltan maderas, y todo tipo de material combustible, para su traslado a los grandes quemaderos extramuros, a fin de ser devastados y convertidos en una espesa cortina de humo negro. Cuenta la leyenda que, en este afán descontrolado por deshacerse de cualquier cosa contaminada, llegó a incluirse en una de las carreras dirigidas a la hoguera una pequeña talla de la Virgen de la Paz. El arriero, conmovido por la sacra imagen, la depositó en la Iglesia de Santiago, último templo antes de encaminarse a la salida de la ciudad, donde hoy permanece 28 . Ciertamente, pocos útiles se libraron de la acción "desinfectante" de las llamas, pues incluso el metal era sometido a esta prueba de salubridad, aunque lo usual en estos casos era emplear baños de vinagre, en especial cuando se trataba de monedas. La lógica consecuencia de esto fue la pérdida de importantes patrimonios, desde aguares modestos a los más lujosos, afectando a talleres de artesanos, a iglesias y su mobiliario, a viviendas señoriales y humildes casas particulares.

Por su parte, los cadáveres eran recopilados y también porteados en grandes carros, aprovechando las horas de nocturnidad, hacia los carneros o grandes fosas comunes. Allí eran depositados en hilera, sobre la cual se echaba una gruesa capa de cal, para descomponer los organismos, y encima otra espesa de tierra para evitar, en lo posible, la evaporación de los humores salidos de la putrefacción. Si todo esto lo reconocemos en la pintura —en la parte izquierda más extrema, a mediación de la altura del lienzo-, en el espacio de la derecha, distinguimos una procesión de figurillas vestidas todas iguales, las mujeres separadas de los hombres, desfilando detrás de la Virgen del Rosario, cuya imagen en andas y portada por los miembros del cabildo civil, asoma junto al hospital. Se trata de los supervivientes de la tragedia, quienes tras someterse a desinfecciones con friegas de vinagre, cortes de pelo y uñas (utilizando para tales prácticas y para el periodo de convalecencia, espacios alejados del centro de población, como la ermita de la Vera-Cruz, dibujada en la parte superior derecha), eran provistos de ropa nueva y marchaban junto a la imagen mariana propiciadora de la salud de los antequeranos en el terrible año de 1679. El cuadro recoge, en concreto, el desfile multitudinario acontecido el 28 de julio tras el cual, la ciudad experimentó una progresiva mejoría al disminuir el número de cesados. Junto a la Virgen se aprecia una pequeña paloma anunciadora de las buenas nuevas, hecho extraordinario recogido por las crónicas locales 29 .

otra parte, los antecedentes, efectos y consecuencias del contagio vienen recogidos en: LEÓN VEGAS, M.: Dos siglos de calamidades públicas en Antequera: Crisis epidémicas y desastres naturales (1599-1804), Antequera, Ayuntamiento, 2007, págs. 159-272.

28 BARRERO BAQUERIZO, F.: Antigüedades de la siempre nobilísima y leal ciudad de Antequera, manuscrito, 1732 , fols. $253 r-254$ r.

29 (A)rchivo (H)istórico (M)unicipal de (A)ntequera, Manifiesto que se hace de la fundación del convento de Predicadores de esta ciudad, traslación a él de la cofradía del Santísimo Rosario, que se hallaba en el Hospital de la Caridad, origen de ésta, sus indulgencias y privilegios y descripción de la Milagrosa Imagen de María Santísima del Rosario, la gran devoción de este pueblo antequerano y milagros especiales de esta celestial Señora su copatrona, protectora y abogada en todas sus aflicciones. 
Este episodio concuerda, perfectamente, con la parte superior de la pintura, y con el carácter programático de la misma. En ella vemos a la Virgen del Rosario en un rompimiento de gloria, rodeada de una corte de ángeles, ante cuya presencia parecen detenerse la lluvia de flechas pestilentes caídas sobre la ciudad hasta ese momento. Su efectiva intercesión se deja ver en el arcoiris dibujado en el cielo como símbolo anunciador de la esperanza y la recuperación de la salud en prueba de la fe demostrada por los antequeranos. De esta forma, se evidencia la causa del azote como un castigo divino por los pecados colectivos del común, mientras la oración conjunta y devoción mariana son la única vía para expiar las culpas y recobrar el premio de la vida, deseo continuamente amenazado en la Edad Moderna por la dureza de los contagios, los conflictos bélicos y precariedad de la producción agrícola.

A tenor de lo apuntado, conviene destacar el cuadro de la epidemia de 1679 como una muestra antropológica interesante, pues de ella se desprende la mentalidad y religiosidad de una época, junto a la realidad sanitaria y precariedad médica de aquellos siglos, aspectos todos ellos extensibles a cualquier población integrada en la Corona española. Su principal valor estriba en ser uno de los pocos testimonios gráficos conservados sobre una tragedia de tales dimensiones, y serlo sin un sentido alegórico o evocador de tiempos muy lejanos sino a modo de crónica, reproduciendo, de forma fidedigna, las líneas de las actas capitulares municipales y sesiones de la Junta extraordinaria de la salud, convocadas a lo largo de 1679. Las cercas o tapias levantadas para aislar el núcleo urbano durante el contagio, las medidas sanitarias empleadas para las cuarentenas, curaciones y convalecencias, o los escasos medios para higienizar los distintos espacios urbanos y casas, tienen cabida en esta singular composición simbólica, incluidos los hechos maravillosos o milagros proveídos gracias a la intercesión mariana, pues las propias autoridades civiles estaban convencidas de ello, o al menos así querían que todo el mundo lo entendiese.

Además de su aportación al conjunto de cuadros versados en la peste, más documental que artística, este caso concreto constituye una importante evidencia sobre el urbanismo de Antequera, donde distinguimos edificios civiles -las casas capitulares en la plaza alta, junto a la bella alcazaba árabe con campanario renacentista-, y religiosos — hospital de San Juan de Dios, los conventos de Santo Domingo y Capuchinos, la iglesia de San Sebastián o la ermita de la Vera-Cruz-, e incluso, los espacios utilizados paras las hogueras depurativas y los enterramientos colectivos, cuya ubicación tras las puertas de acceso a la ciudad (de Málaga y Granada, respectivamente), corresponde con los hallazgos arqueológicos de los últimos años y la datación de los restos humanos encontrados allí, con todavía partículas de óxido cálcico.

En suma, el valor del cuadro analizado reside en sumarse a la nómina de representaciones sobre una catástrofe vírica concreta, situándola en un contexto espacio-temporal preciso, lo que la convierte en una efeméride imborrable en la memoria de los antequeranos y de todas aquellas poblaciones andaluzas tocadas por el mal, en el fatídico año de 1679. 